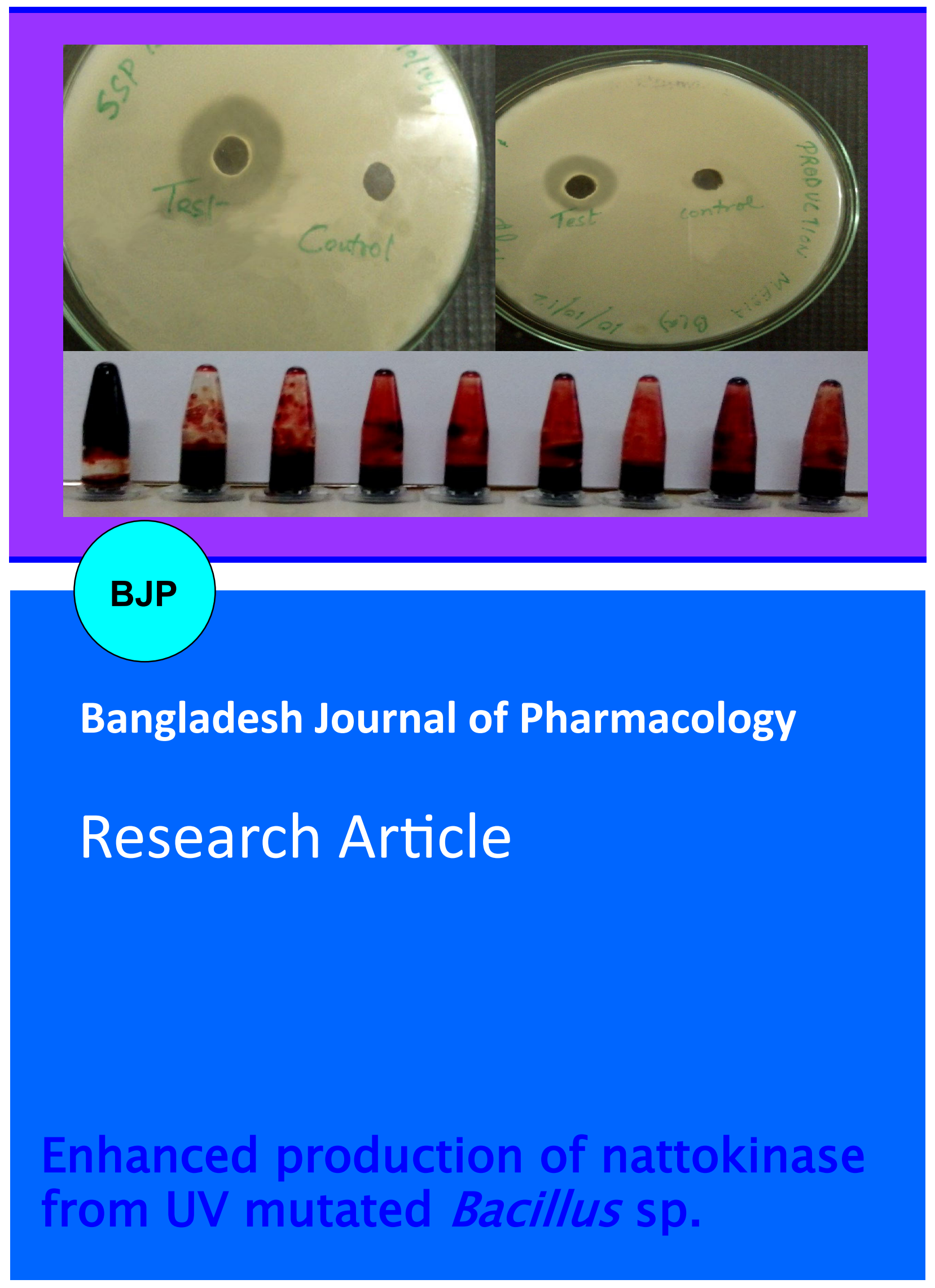


Abstracted/indexed in Academic Search Complete, Agroforestry Abstracts, Asia Journals Online, Bangladesh Journals Online, Biological Abstracts, BIOSIS Previews, CAB Abstracts, Current Abstracts, Directory of Open Access Journals, EMBASE/Excerpta Medica, Global Health, Google Scholar, HINARI (WHO), International Pharmaceutical Abstracts, Open J-gate, Science Citation Index Expanded, SCOPUS and Social Sciences Citation Index

ISSN: 1991-0088

\title{
Enhanced production of nattokinase from UV mutated Bacillus sp.
}

\author{
V. Mohanasrinivasan, C. Subathra Devi, Ritusree Biswas, Falguni Paul, Mohor Mitra, \\ E. Selvarajan and V. Suganthi
}

Division of Environmental Biotechnology, School of Bio Sciences and Technology, VIT University, Vellore 632014, India.

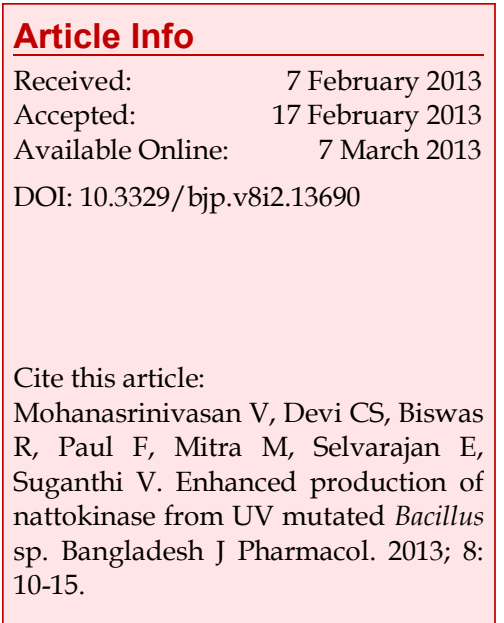

\begin{abstract}
In the recent years, nattokinase is one of the most-often employed among the several thrombolytic agents used clinically, particularly because of its lower cost comparing to other thrombolytic agents. In the present research work, Bacillus sp. was isolated from the heterogeneous microbial population present in the soil sample and screened for the production of nattokinase. The production of the enzyme was carried out using two different media (with and without shrimp shell substrate). Nattokinase activity (clot buster) was determined by using a modified Holmstorm method. The production strain SFN01 was improved by random mutagenesis (UV radiation) and the enzyme activity was checked with the enzyme produced by wild strain. The mutated strains had exhibited a higher clot lysis activity in which 1 unit of the enzyme completely lyses $1 \mathrm{~mL}$ of human blood when compared to the wild strain. Nattokinase produced by SFN showed a retention time of $10.6 \mathrm{~min}$ in RPHPLC chromatogram.
\end{abstract}

\section{Introduction}

Myocardial infarction is the most common contributor of morbidity and mortality worldwide. Stroke is the third leading cause of death. According to World Health Organization, nearly 8 million people worldwide suffer from myocardial infarction and in India approximately 2.5 crores of people exist. In India, 31.7\% of deaths occur due to MI. Incidence of cardiovascular disease was about 7\% in 1970 and increased up to $32 \%$ in 2011 in India (Reddy, 2007). Enzyme therapies are becoming more prevalent in medicine today, with many manufacturers targeting their advantages in disease treatment. In the last 100 years, enzymes have been increasingly used to treat various cardiovascular diseases. Nature has designed a system the body uses to maintain and repair itself. When the vascular system is injured the body responds quickly to stop the bleeding and repair the damage. Circulating platelets are called into action to quickly seal the leak by forming a blood clot. Not all blood clot is desirable. Thrombosis is an abnormal blood clot inside a blood vessel. The blood clots can detach from the vascular wall and travel in the blood. These free floating thrombi (now called emboli) can lodge anywhere in the cardiovascular system, including the lungs or brain (as in a thrombotic stroke). It is fibrin that is implicated in many heart attacks, since cardiac arrest usually occurs after a plaque's cap fractures, causing a blood clot to form over the fracture and block blood flow. Nattokinase is an ideal treatment, therefore, for heart attack patients, ischemic stroke patients, and for those who are at risk of pulmonary embolism or deep vein thrombosis-in short, and for any patient with a clotting problem.

The major thrombolytic agents are classified into two types. The first one is the plasminogen activators, such as urokinase, and the second one is tissue type plasminogen activator (tPA), streptokinase, and both activate plasminogen to plasmin, and the plasmin like proteins, such as nattokinase and lumbrikinase, which can directly degrade the fibrin. The enzyme nattokinase offers a completely natural means of helping to prevent and dissolve blood clots. It closely resembles plasmin. 
So far, many researchers have focused their efforts on the isolating and screening of microorganisms for enzyme production with high fibrinolytic activity (Chang et al., 2000), as well as on the purifying and characterizing of newly found enzyme (Kim et al., 1996). Evidences suggest that B. subtilis secrete nattokinase. NK is primarily found from a traditional fermented soybean food named as "Natto" in Japan (Sumi et al., 1987). It is a subtilisin-like serine protease with molecular weight of 27,000-42,000 Da (Chang et al., 2000; Fujita et al., 1993; Kim et al., 1996; Peng et al., 2003). Besides in vitro tests of fibrinolytic activity, many in vivo studies had been reported. (Fujita et al., 1995) treated dogs with nattokinase by oral administration, and the fibrinolytic activity in plasma increased and showed that subtilisin NAT could pass the rat intestinal tract and dissolve the chemically induced thrombosis. (Suzuki et al., 2003) found that dietary supplementation of Natto suppressed intimal thickening and modulated the lysis of mural thrombi after endothelial injury in rat femoral artery. Furthermore, NK can cleave active recombinant prokaryotic plasminogen activator inhibitor into low molecular weight fragments (Urano et al., 2001). Those researches imply that NK is useful as a promising thrombolytic agent (Sumi et al., 1990).

In this paper we report on the isolation and screening of nattokinase producing bacillus $\mathrm{sp}$ from soil. UV mutation was also carried out for isolated Bacillus sp. The nattokinase was extracted and precipitated for both normal and UV mutated Bacillus sp and the clot buster activity was studied.

\section{Materials and Methods \\ Isolation and morphological characterization of Bacillus $s p$}

Soil sample was collected from VIT garden and serially diluted to $10^{-6}$. Spread plate technique was performed on Nutrient Agar and incubated at $37^{\circ} \mathrm{C}$ for 24 hours. The bacterial colonies were selected based on the colony morphology. Pure culture was made and stored at $4^{\circ} \mathrm{C}$. To determine the external morphology of the isolation, Grams reaction was performed.

\section{Radial caseinolytic assay}

Screening for nattokinase was done using nutrient media supplemented with $2 \%$ casein. Culture supernatants were obtained by centrifuging the production media. Wells were made on the solidified casein media using a sterile cork borer (each with one test and one control). $100 \mu \mathrm{L}$ of the culture supernatants were added and the plates were refrigerated for 4 hours to allow the radial diffusion of the compounds contained in the supernatant prior to incubation for 24 hours at $37^{\circ} \mathrm{C}$.

Production of nattokinase (Dubey et al., 2011)
For nattokinase production, two different types of production media were prepared for comparative studies. Production media supplemented with shrimp shells was prepared and $1 \%$ inoculum from nutrient broth was transferred to it. It was then incubated in the shaker at $37^{\circ} \mathrm{C}$ for 2 days. Simultaneously production media without shrimp shell substrate was also prepared and inoculated with $1 \%$ inoculum from nutrient broth. It was incubated in the shaker at $37^{\circ} \mathrm{C}$ for 7 days.

\section{Enzyme separation and precipitation}

For the separation of enzyme, the production media was centrifuged at $8,000 \mathrm{rpm}$ for $20 \mathrm{~min}$ in a cooling centrifuge at $4^{\circ} \mathrm{C}$. Supernatant was collected, which served as the crude enzyme, and used for the enzyme assays and precipitation.

The crude supernatant was subjected to ammonium sulfate precipitation. 30 and $80 \%$ of ammonium sulfate was added to each sample with constant stirring for 15 min in magnetic stirrer followed by centrifugation at 10,000 rpm for $30 \mathrm{~min}$. Supernatant was collected and dissolved in 1x phosphate buffer saline. Both the crude and the precipitated enzymes were used to determine the plasmolytic and thrombolytic activity.

\section{Enzyme assay}

Plasmolytic activity of the extracted enzyme was determined by the Heated Plasma Agar assay. Nutrient agar was prepared, human blood was freshly collected and an anti-coagulant (heparin) was added to it. It was then centrifuged at $10,000 \mathrm{rpm}$ for $10 \mathrm{~min}$. Blood plasma (supernatant) was drawn out and kept in the water bath for $20 \mathrm{~min}$ at $56^{\circ} \mathrm{C}$. The heated plasma was then cooled to optimum temperature and added to nutrient agar and mixed well by shaking. The resulting media was poured into sterile petriplates. Wells were made on the solidified media using a sterile cork borer (each with one test and one control). $100 \mu \mathrm{L}$ of the culture supernatants were added and the plates were refrigerated for 4 hours to allow the radial diffusion of the compounds contained in the supernatant prior to incubation for 24 hours at $37^{\circ} \mathrm{C}$.

\section{Determination of enzyme activity}

Modified Holmstorm method (Holmstorm, 1965) was used to determine the enzyme activity. Human blood was freshly collected and poured into $1.5 \mathrm{~mL}$ eppendorf tubes (each tube containing $1 \mathrm{~mL}$ blood). When the blood clotted completely, crude as well as precipitated enzyme solutions were added in increasing concentrations, i.e, $10,20,30 \mu \mathrm{L}$ and so on up to $100 \mu \mathrm{L}$ separately. After incubating it for 18 hours at $37^{\circ} \mathrm{C}$, the tubes were inverted to check the extent of lysis, and the clot lysis activity was determined.

\section{Strain improvement technique}

Since, we observed better lysis of the clots by the strain 
grown in shrimp shell supplemented media and proceeded to carry out strain improvement of the same.

Isolated colonies of Bacillus sp SFN were suspended in 1X PBS and exposed to UV for 2.5, 5, 7.5 and $10 \mathrm{~min}$ (Thaer et al., 2005). These plates were kept $20 \mathrm{~cm}$ away from the UV lamp (at a wavelength of $254 \mathrm{~nm}$ ). After the exposure, the suspension was stored overnight in the dark to avoid photo reactivation. Mutated samples were inoculated into the shrimp shell supplemented media and incubated for 2 days at $37^{\circ} \mathrm{C}$. Ammonium sulphate precipitation was carried with the culture supernatants using 30, 70 and $80 \%$ ammonium sulfate. Samples were then used to perform Holmstorm method to determine the clot lysis activity. A lower concentration of the enzyme (1 to $10 \mu \mathrm{L}$ ) was used this time to compare the efficiency of the enzyme produced by the mutated strains. Extent of lysis was checked after incubating it for 18 hours at $37^{\circ} \mathrm{C}$.

\section{High performance liquid chromatography}

The precipitated sample of Bacillus sp SFN was subjected to RP-HPLC. The chromatographic conditions used are as follows: Chromatographic column: C18. Mobile phase: $0.2 \mathrm{~mol} / \mathrm{L}$ of $\mathrm{NaH}_{2} \mathrm{PO}_{4}-\mathrm{CH}_{3} \mathrm{OH}$ (95:5). Flow rate: $1 \mathrm{~mL} / \mathrm{min}$. Detection wavelength: $220 \mathrm{~nm}$. Total run time: $20 \mathrm{~min}$. Elution peaks were collected and the enzyme purity was determined (Wang et al., 2009) .

\section{Results and Discussion}

Our continuous search for Bacillus sp. from soil led to the isolation of one strain of Bacillus which was named as SFN (Search for nattokinase). The Bacillus culture was maintained as pure culture in nutrient agar for further studies. The colony morphology of SFN was creamish, almost circular, flat opaque colonies. The Gram reaction of the SFN colony was found to be gram positive, rod shaped and in pairs.

The screening of nattokinase production was determined by performing the caseinolytic assay. Bacillus $s p$ SFN showed caseinolytic activity on nutrient agar supplemented with $2 \%$ casein since the proteolytic enzyme produced by Bacillus sp SFN utilized the casein present in the media. SFN grown in shrimp shell production media showed better activity than Bacillus $s p$ SFN grown on production media without shrimp shell showed comparatively less activity (Figure 1).

The plasmolytic activity was checked by the heated plasma agar assay. The enzyme produced by Bacillus sp SFN showed plasmolytic activity on nutrient agar supplemented with blood plasma. Bacillus sp SFN grown in shrimp shell production media showed better activity than the Bacillus $s p$ SFN grown on production media without shrimp shell showed comparatively less activity (Figure 2).

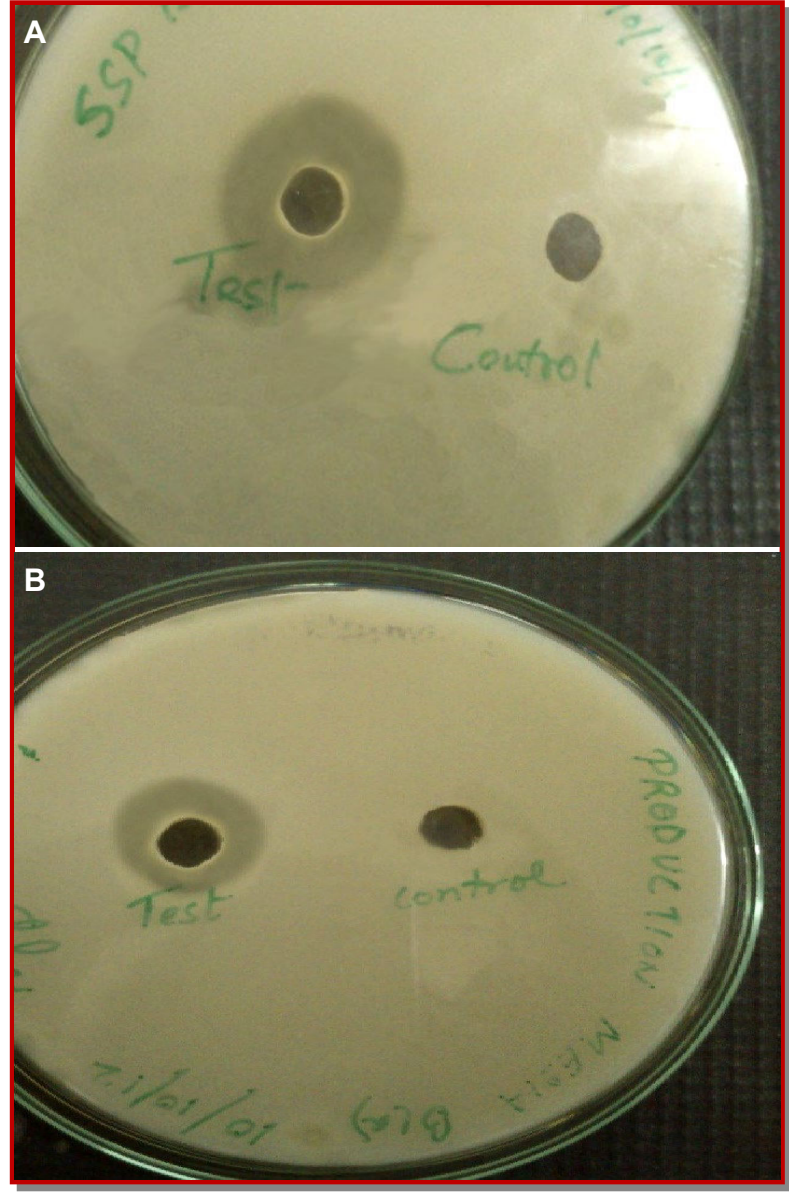

Figure 1: Caseinolytic activity of SFN on production media (A) with shrimp shell or (B) without shrimp shell

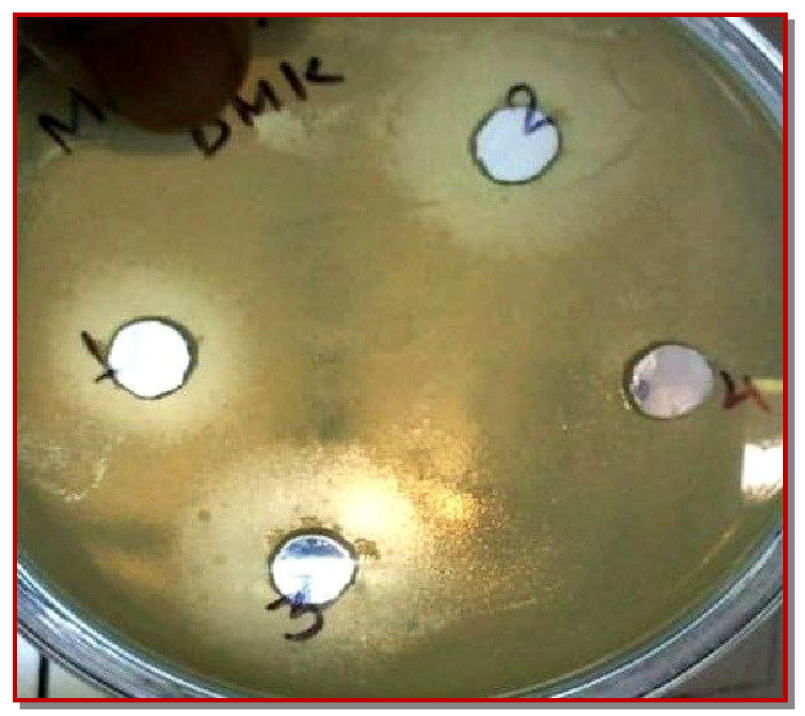

Figure 2: The plate shows zone of clearance where 1 represents Bacillus sp SFN crude in production media without shrimp shell, 2 and 3 represent Bacillus sp SFN crude in production media with shrimp shell and 4 as control 


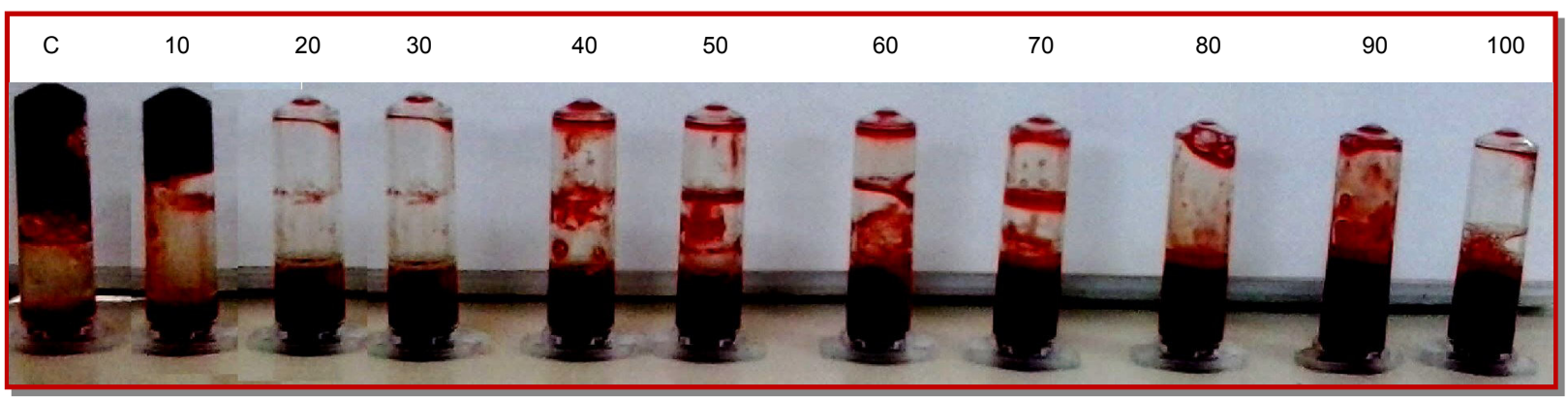

Figure 3: Holmstorm method for Bacillus sp SFN crude supernatant in production media without shrimp shell (10 to $100 \mu \mathrm{L})$

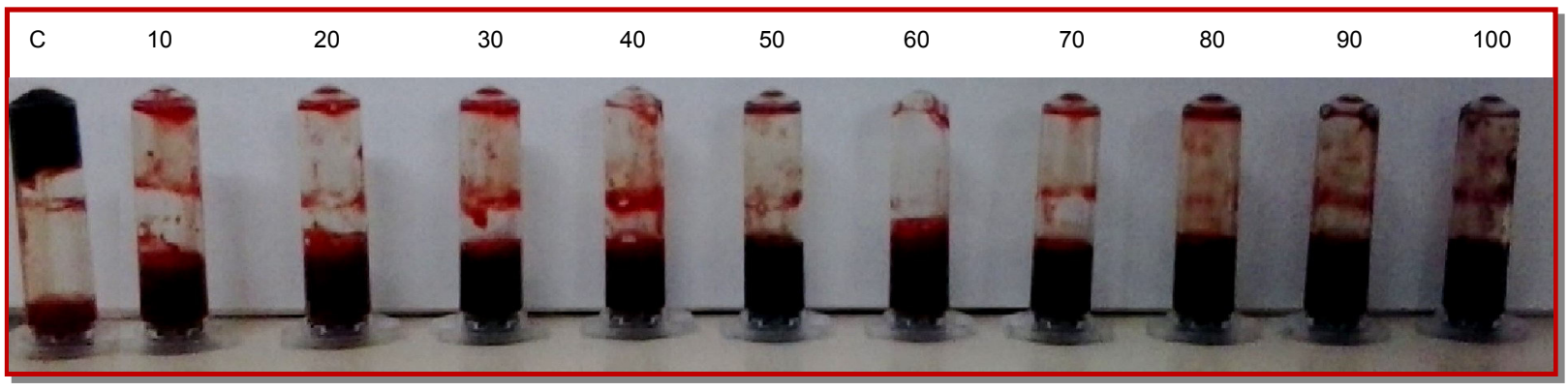

Figure 4: Holmstorm method for Bacillus sp SFN crude supernatant in production media with shrimp shell (10 to $100 \mu \mathrm{L})$

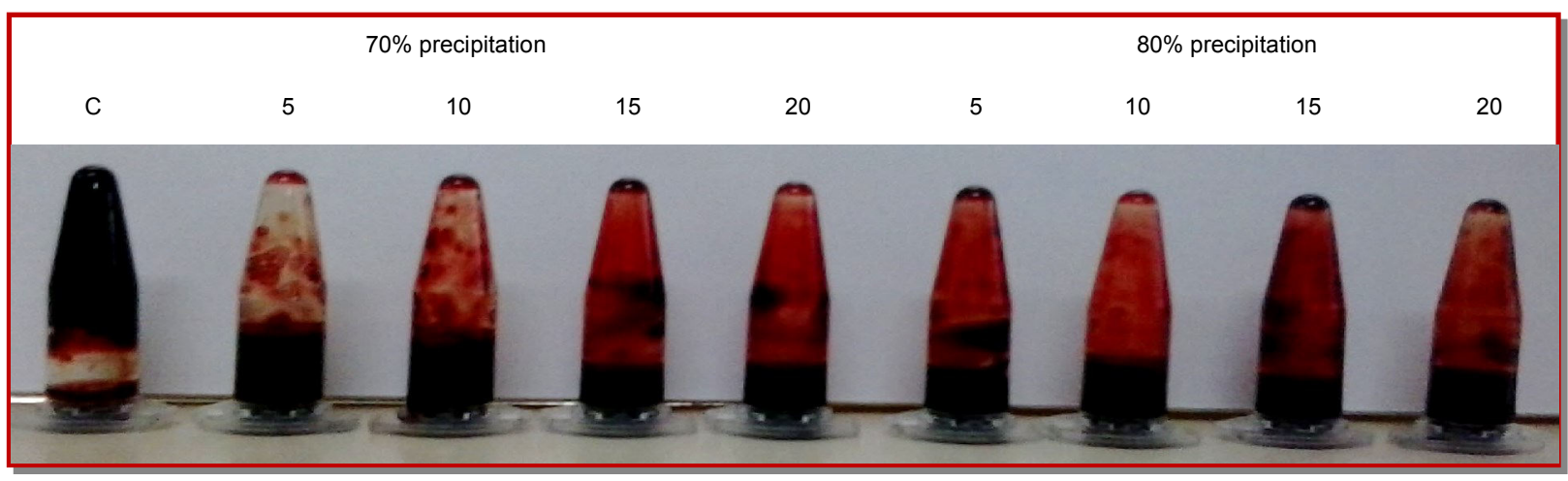

Figure 5: Holmstorm method for Bacillus sp SFN precipitates in production media without shrimp shell $(5,10,15,20 \mu \mathrm{L})$

In the holmstorm method, the extent of lysis was checked after the coagulation of blood, in order to determine the enzyme activity. One unit of enzyme activity was defined as the minimum amount of enzyme at which the blood clot lyses completely.

Both the samples Bacillus sp SFN produced in shrimp shell media showed lysis of blood starting from 10 to 100 units. But the Bacillus sp SFN produced in production media showed lysis starting from 20 to 100 units. The following Figure 3 and Figure 4 show lysis after incubation at $37^{\circ} \mathrm{C}$ for 18 hours.

Therefore, enzyme produced by Bacillus sp SFN in shrimp shell media showed better clot lysis activity, than the production media without shrimp shell.

The samples produced in media without shrimp shell and shrimp shell supplemented media were subjected to ammonium sulfate precipitation and with the 70 and $80 \%$ precipitates this Holm storm method was carried out.

The 70 and $80 \%$ precipitates of the enzyme produced by Bacillus sp SFN in production media which was added in concentrations of 5, 10, 15 and 20 units showed complete lysis after an incubation period of 18 hours shown in Figure 5.

Similarly the 70 and $80 \%$ precipitated enzymes produced by Bacillus sp SFN in shrimp shell media gave complete lysis in all four concentrations (Figure 6).

The Bacillus sp. SFN grown in shrimp shell showed good result in all the assays. Thus, the Bacillus sp. SFN was mutated by UV-radiation and Holmstorm method was performed.

Clot lysis activity was observed in both 5 and $10 \mathrm{~min}$ when exposed to $\mathrm{UV}$ radiation. Thus, $5 \mathrm{~min}$ of $\mathrm{UV}$ exposure was better for the clot lysis by Bacillus sp SFN (Figure 7, Figure 8). 


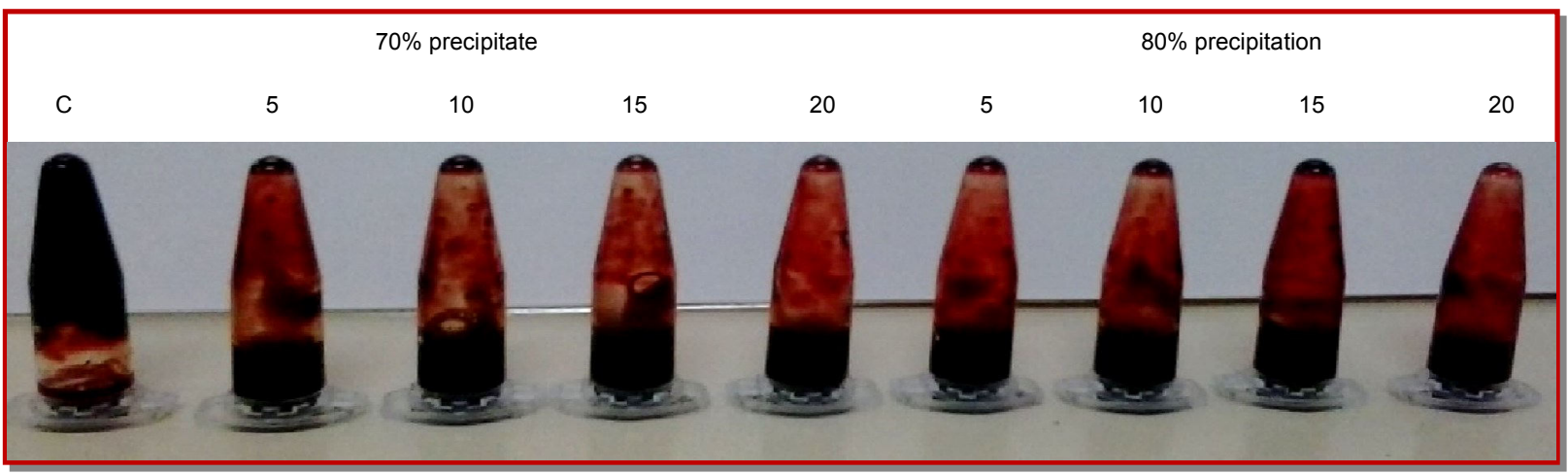

Figure 6: Holmstorm Method for Bacillus sp SFN precipitates in production media with shrimp shell $(5,10,15,20 \mu \mathrm{L})$

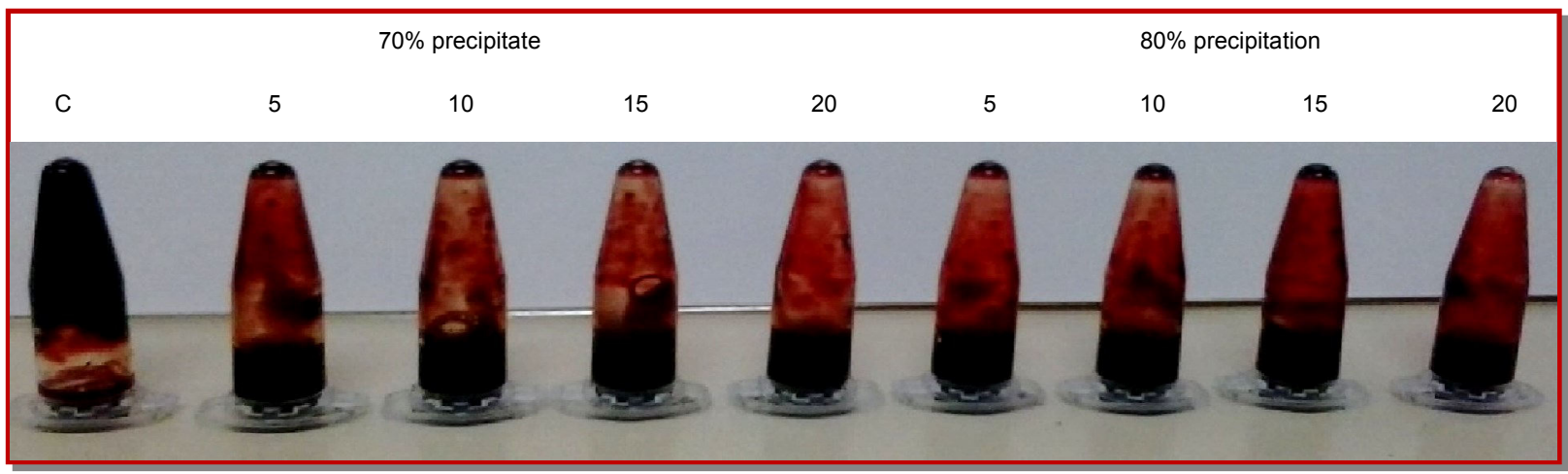

Figure 7: Holmstorm Method for Bacillus sp SFN mutated (5 min) precipitates in production media with shrimp shell (1 to $10 \mu \mathrm{L})$

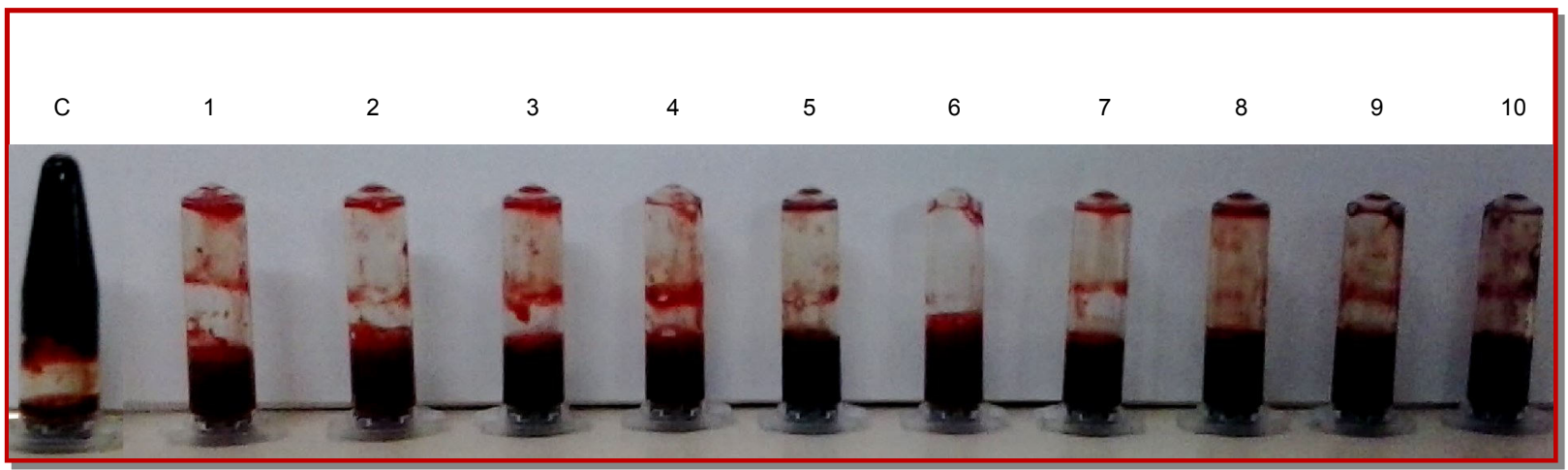

Figure 8: Holmstorm Method for Bacillus sp SFN mutated (10 min) precipitates in production media with shrimp shell (1 to $10 \mu \mathrm{L})$

Thereby, it can be concluded from the result that 5 and $10 \mathrm{~min}$ of exposure time to the mutagen was the most effective in producing favorable mutation that produced nattokinase with a higher activity than the wild strain.

The concentrations of nattokinase obtained from the standard graph are as follows: a) Non mutated Bacillus $s p$ SFN precipitates (grown in shrimp shell supplemented medium) was $570 \mu \mathrm{g} / \mathrm{min}$; b) Mutated (5 min) Bacillus sp SFN precipitates (grown in shrimp shell supplemented medium) was $460 \mu \mathrm{g} / \mathrm{mL}$; c) Mutated (5 min) Bacillus sp SFN crude (grown in shrimp shell substituted medium) was $490 \mu \mathrm{g} / \mathrm{mL}$.

Chromatogram obtained for nattokinase produced by
Bacillus sp SFN was compared with standard. The retention time of the nattokinase was found to be 10.6 min.

\section{Conclusion}

UV irradiation is an effective mutagenic agent for strain improvement of Bacillus sp. and its enhanced nattokinase activity. One unit of the enzyme from the mutated strain has been found to lyse the clot completely. This could hold great value for the future which would enable one to obtain high yielding mutant strains of these isolations for large scale production of nattokinase. 


\section{References}

Besson F, Michel G. Mycosubtilins B and C: Minor antibiotics from mycosubtilin producer Bacillus subtilis. Int Microbiol. 1990; 62: 93-99.

Chang CT, Fan MH, Kuo FC, Sung HY. Potent fibrinolytic enzyme from a mutant of Bacillus subtilis IMR-NK1. J Agric Food Chem. 2000; 48: 3210-16.

Chung S, Kong H, Buyer JS, Lakshman DK, Lydon J, Kim SD, Roberts DP. Isolation and partial characterization of Bacillus subtilis ME488 for suppression of soil borne pathogens of cucumber and pepper. Appl Microbiol Biotechnol. 2008; 80: 115-23.

Dubey R, Kumar J, Agrawala D, Char T, Pusp P. Isolation, production, purification, assay and characterization of fibrinolytic enzymes (nattokinase, streptokinase and urokinase) from bacterial sources. Afr J Biotechnol. 2011; 10: 1408-20.

Fiddaman PJ, Rossall S. The production of antifungal volatiles by Bacillus subtilis. J Appl Bacteriol. 1993; 74: 119-26.

Fujita M, Nomura K, Hong K, Ito Y, Asada A, Nishimuro S. Purification and characterization of a strong fibrinolytic enzyme (nattokinase) in the vegetable cheese natto, a popular soybean fermented food in Japan. Biochem Biophys Res Commun. 1993; 197: 1340-47.

Fujita M, Hong K, Ito Y, Fuji R, Kariya K, Nishimuro S. Thrombolytic effect of nattokinaseon a chemically induced thrombosis model in rat. Biol Pharmaceut Bull. 1995b; 18: 1387-91.

Holmstrom B. Streptokinase assay on large agar diffusion plates. Acta Chem Scand. 1965; 19: 1549-54.

Kim W, Choi K, Kim Y, Park H, Choi J, Lee Y, Oh H, Kwon I,
Lee S. Purification and characterization of a fibrinolytic enzyme produced from Bacillus sp. strain CK 11-4 screened from Chungkook-Jang. Appl Environ Microbiol. 1996; 62: 2482-88.

Klich MA, Lax AR, Bland JM. Inhibition of some mycotoxigenic fungi by iturin A, a peptidolipid produced by Bacillus subtilis. Mycopathologia 1991; 116: 77-80.

Peng Y, Huang Q, Zhang RH, Zhang YZ. Purification and characterization of a fibrinolytic enzyme produced by Bacillus amyloliquefaciens DC-4 screened from douchi, a traditional Chinese soybean food. Comp Biochem Physiol. Part B: Biochem Molecular Biol. 2003; 134: 45-52.

Reddy KS. India wakes up to threat of cardiovascular disease. J Am Coll Cardiol. 2007; 50: 1370-72.

Sumi H, Hamada H, Nakanishi K, Hiratani H. Enhancement of the fibrinolytic activity in plasma by oral administration of nattokinase. Acta Haematologica. 1990; 84: 139-43.

Sumi H, Hamada H, Tsushima H, Mihara H, Muriki H. A novel fibrinolytic enzyme (nattokinase) in the vegetable cheese natto: A typical and popular soybean food in the Japanese diet. Experientia 1987; 43: 1110-11.

Thaer TAA, Adinarayana K, Poluri E. Isolation and mutagenesis of Streptokinase producing bacteria. Am J Immunol. 2005; 4: $125-29$.

Urano T, Ihara H, Umemura K, Suzuki Y, Oike M, Akita S, Tsukamoto Y, Suzuki I, Takada A. The profibrinolytic enzyme subtilisin NAT purified from Bacillus subtilis cleaves and inactivates plasminogen activator inhibitor type 1. J Biol Chem. 2001; 276: 24690-96.

Wang C, Du M, Zheng D, Kong F, Zu G, Feng Y. Purification and characterization of nattokinase from Bacillus subtilis Natto B-12. J Agric Food Chem. 2009; 57: 9722-29. 